\title{
Desaparecimento de abelhas polinizadoras nos sistemas naturais e agrícolas: Existe uma explicação?
}

\author{
Disappearance of pollinating bees in natural and agricultural systems: Is there an explanation? \\ Joatan Machado da Rosa ${ }^{1 \star}$, Cristiano João Arioli², Patricia Nunes-Silva ${ }^{3}$ \& Flávio Roberto Mello \\ Garcia $^{4}$
}

1Universidade do Estado de Santa Catarina, Lages, SC, Brasil. *Autor para correspondência: joatanmachado@gmail.com.

${ }^{2}$ Empresa de Pesquisa Agropecuária e Extensão Rural de Santa Catarina, São Joaquim, SC, Brasil.

${ }^{3}$ Instituto Tecnológico Vale, Belém, PA, Brasil.

${ }^{4}$ Universidade Federal de Pelotas, Pelotas, RS, Brasil.

Submissão:22/08/2017 | Aceite: 29/08/2018

\begin{abstract}
RESUMO
Desde a última década é notório o desaparecimento das populações de abelhas polinizadoras em diversos países. Esse grupo é responsável pela polinização e manutenção de centenas de espécies vegetais usadas na alimentação humana, além de contribuir de forma expressiva para o desenvolvimento socioeconômico de comunidades associadas à agricultura familiar. Neste trabalho, são discutidas as possíveis causas do desaparecimento, entre as quais se destacam: o desmatamento, reforçado pela carência de flora natural, o manejo inadequado de colmeias, as crescentes infestações de pragas nas colônias e o uso de agrotóxicos. Sugerem-se estratégias para a conservação de abelhas nativas e domesticadas, merecendo destaque: (a) a conservação da paisagem natural circundante às áreas agrícolas; (b) a profissionalização de apicultores no manejo nutricional e de conservação das colmeias; e (c) o contínuo desenvolvimento de estudos criteriosos sobre o efeito letal e subletal de agrotóxicos sobre os polinizadores.
\end{abstract}

PALAVRAS-CHAVE: polinização, intoxicação, desmatamento, patógenos e ácaros.

\begin{abstract}
Since the last decade, the disappearance of pollinating bee populations has been apparent in several countries. This group is responsible for the pollination and maintenance of hundreds of plant species used in human food, in addition to contributing significantly to the socioeconomic development of several communities associated to family farming. In this study, the possible causes of this disappearance are discussed, among which we highlight deforestation, reinforced by the lack of natural flora, inadequate hive management by beekeepers, increasing infestations of pests in the colonies, and the use of agrochemicals. Conservation strategies for native and domesticated bees are suggested, namely: (a) maintenance of the natural landscape that surrounds agricultural areas; (b) beekeepers' professionalization in the nutritional management and conservation of beehives; and (c) the continuous development of detailed studies about the lethal and sublethal effects of agrochemicals on pollinators.
\end{abstract}

KEYWORDS: pollination, poisoning, deforestation, pathogens and mites.

\section{INTRODUÇÃO}

A interação entre abelhas e plantas garantiu aos vegetais o sucesso na polinização cruzada, que se constituiu uma importante adaptação evolutiva das plantas, aumentando o vigor das espécies, possibilitando novas combinações de fatores hereditários e aumentando a produção de frutos e sementes (COUTO \& COUTO 2002). Há mais de 60 milhões de anos, as abelhas habitam a terra. Dentro desse longo período, várias características evolutivas tornaram esses organismos um dos sistemas mais importantes de suporte à vida. Estima-se existirem cerca de 20 mil espécies de abelhas, contudo este esse número pode ser duas vezes maior, sendo necessário realizar estudos de levantamento das abelhas e as interações abelha-planta nos diversos biomas (ROUBIK 1992).

As abelhas constituem o grupo economicamente mais importante de polinizadores em todo o mundo. Trinta e cinco por cento da produção mundial de alimentos depende de polinizadores (KLEIN et al. 2007), e 
as abelhas colaboram de maneira bastante expressiva, atuando como agentes de polinização em aproximadamente $73 \%$ das espécies vegetais cultivadas no mundo (RICKETTS et al. 2008).

Um exemplo de dependência obrigatória é a polinização da macieira. De acordo com LOSEY \& VAUGHAN (2006), essa cultura é 100\% dependente das abelhas. Em casos extremos, plantas fortemente autoincompatíveis não formam frutos e sementes a partir de flores autopolinizadas. Porém, na maioria dos casos, a autoincompatibilidade se expressa por baixa produtividade de frutos e sementes em autopolinizações quando comparadas com polinizações cruzadas. Vale ressaltar que, muitas vezes, o pólen da própria flor ou planta precisa ser depositado na superfície estigmática das flores por intermediação das abelhas mesmo que haja autocompatibilidade (ORTH et al. 2012).

As abelhas Apis mellifera L. (Hymenoptera: Apidae) têm sido as mais utilizadas em todo o mundo para a polinização de plantas cultivadas em razão de seu fácil manejo, do tamanho de suas colônias, de sua abundância em diferentes ecossistemas e de seu perfil generalista na busca de recursos. Some-se a tais benefícios a importância que representam em termos de produção de mel e de outros produtos apícolas (PIRES et al. 2016). Por outro lado, GARIBALDI et al. (2013) enfatizam que os serviços de polinização nas áreas agrícolas não dependem apenas das espécies de abelhas domesticadas, mas também das populações de abelhas silvestres que estão presentes nos mais variados ambientes.

Nas últimas décadas, inúmeros relatos do desaparecimento de colônias manejadas têm sido divulgados referentes aos anos de 1880, 1920 e 1960. Esses desaparecimentos foram conhecidos como Mal de outono, Colapso de outono, Doença de Maio e Doença do desaparecimento, com descrições semelhantes ao que hoje pesquisadores denominam Transtorno do Colapso das Colônias (CCD, Colony Collapse Disorder) (PAREJA et al. 2011), porém sem a magnitude e velocidade dos acontecimentos mais recentes.

A busca incessante por produtividade agrícola tem colaborado para o uso de procedimentos que afetam diretamente as populações de polinizadores. Entre esses procedimentos destacam-se 0 uso constante de agrotóxicos, o manejo incorreto de colmeias, a baixa variabilidade genética que afeta diretamente a resistência dos polinizadores ao ataque de pragas, além do desmatamento, que, segundo SALA et al. (2000), é considerado o principal fator relacionado à extinção de espécies.

\section{Efeito do desmatamento na manutenção de colmeias}

Muitos são os impactos das atividades antrópicas sobre os recursos naturais. Pode-se considerar a modificação da paisagem natural por desmatamentos como um dos mais expressivos, pois fragmenta os ecossistemas e substitui a vegetação nativa pelo plantio de pastagem para pecuária mais intensiva, pelos cultivos de grãos e frutas, pelos reflorestamentos e pelas edificações (SILVA et al. 2010). Em estudos recentes na Amazônia, BROWN \& OLIVEIRA (2014) verificaram uma relação significativa entre o desmatamento e a redução na riqueza de espécies de abelhas sem ferrão, as quais são de suma importância para a manutenção de diversas espécies vegetais na região.

Essa fragmentação, que tem origem dos desmatamentos, é considerada um dos fatores que mais contribuem para a redução da diversidade de abelhas. Paisagens homogêneas e pobres são reflexo direto da destruição do habitat pela intensificação agrícola (TILMAN et al. 2001). Tornam-se cada vez mais escassos os recursos necessários à sobrevivência desses insetos, como locais para nidificação, alimento e outras condições físicas (MARCO JR \& COELHO 2004), o que acaba comprometendo a sobrevivência desses polinizadores.

Assim como as abelhas silvestres, as abelhas manejadas também dependem da vegetação nativa para assegurar a sobrevivência de seus enxames, garantindo reserva de mel e pólen. Estudos realizados por pesquisadores evidenciam a importância da preservação das condições ambientais e da utilização desses insetos como polinizadores, potencializando a qualidade e quantidade econômica de diversas culturas (KLEIN et al. 2007). Da mesma forma, a ausência de um grupo particular de polinizadores pode ocasionar uma falha reprodutiva, que, em última instância, leva à exclusão de plantas dependentes do serviço de polinização das comunidades naturais (NEFF \& SIMPSON 1993).

Dessa forma, os processos antrópicos de destruição de espécies vegetais nativas comprometem os estoques de néctar e pólen, reduzindo o serviço realizado por polinizadores que naturalmente ocupam esses ambientes (BIESMEIJER et al. 2006). Corroborando isso, ambientes pobres em diversidade de abelhas tendem à estagnação, à redução do número de espécies vegetais presentes ou até mesmo à entrada em colapso do ecossistema.

\section{Manejo intensivo das colmeias}

Atualmente, a densidade populacional de muitos polinizadores está sendo reduzida a níveis que podem sustar os serviços de polinização nos ecossistemas naturais e agrícolas e a manutenção da 
capacidade reprodutiva de plantas silvestres (KREMEN et al. 2004). Na ausência de espécies polinizadoras nativas, a espécie $A$. mellifera vem desempenhando um papel fundamental ao reduzir 0 deficit de polinização em diversas culturas. Dessa forma, o manejo desse polinizador configura-se como uma ferramenta importante tanto para a implementação de ações de conservação como para incrementar a produção em cultivos agrícolas dependentes de polinização por insetos.

Em função do baixo valor do mel pago aos produtores, da intensa urbanização e da expansão de novas fronteiras agrícolas, a produção mundial de mel tem reduzido. Esses fatores levam muitos apicultores a buscar fontes de renda alternativas. A principal delas é o aluguel das colmeias para polinização de cultivos. Citamos como exemplo o aluguel de colônias para a polinização de cultivos de amêndoas nos Estados Unidos e para a cultura da macieira no sul do Brasil. Entretanto, esse manejo e o transporte de colmeias para culturas diferentes dos habituais podem causar estresse às abelhas, o que prejudica 0 desenvolvimento, a condição nutricional e a produção da colônia em anos subsequentes. Nesses monocultivos em que as colmeias são instaladas para a polinização, nem sempre são observadas fontes de água de qualidade para as abelhas. Além disso, em regiões quentes, a falta de sombreamento nesses locais pode comprometer o desenvolvimento adequado da colônia.

Quando as abelhas saem do seu local de origem e são direcionadas para outras culturas, elas devem alimentar-se de pólen de alta qualidade para restaurar os níveis de proteína no corpo. Esse objetivo pode ser alcançado transportando as abelhas para locais com excelentes recursos florais ou alimentando-as. Presumivelmente, isso nem sempre é feito (OLDROYD 2007).

Segundo BRODSCHNEIDER \& CRAILSHEIM (2010), as deficiências nutricionais nas colônias podem prejudicar as reservas de alimento. Com isso, os cuidados com as crias podem ser afetados, aumentando o canibalismo e influenciando diretamente no estado nutricional das gerações subsequentes de operárias. Esses acontecimentos comprometem de forma direta e indireta o desenvolvimento da colônia, suprimindo os mecanismos naturais de defesa das abelhas, bem como a manutenção do número adequado de abelhas em cada casta.

Pelas suas características, uma apicultura bem-sucedida deve possibilitar o retorno socioeconômico, com aumento da renda familiar e estar em consonância com as necessidades inerentes à atividade e às necessidades de preservação da biodiversidade de flora e fauna. O desconhecimento ou a não adoção de manejo adequado na apicultura repercute em diversos problemas no apiário. Entre eles, pode-se destacar a redução do índice populacional das colmeias, a maior incidência de problemas sanitários e a queda na produção de mel, pólen e própolis (SILVA 2004).

\section{Inimigos naturais das abelhas}

O comércio mundial e a troca de bens e mercadorias entre países aceleraram a disseminação de pragas e agentes patogênicos que acometem as populações de abelhas ao redor do mundo. Nesse panorama, sugere-se que a saúde dos polinizadores domésticos, como $A$. mellifera, receba cada vez mais atenção. Além dos pesticidas e do desmatamento, outros fatores são apontados como precursores dos recentes declínios das populações de abelhas, como os agentes patogênicos virais, bactérias, fungos e ácaros parasitas (GOULSON et al. 2015, POTTS et al. 2016). Segundo PEREIRA et al. (2004), as doenças nas abelhas (Apis mellifera L.) exercem efeitos deletérios sobre o seu desenvolvimento e a sua produtividade, o que pode acarretar em prejuízo para o apicultor e para o ecossistema.

MESSAGE et al. (2012) relatam que diversos parasitas, patógenos e predadores são capazes de acometer as colônias de abelhas melíferas. Entre eles, os autores destacam os protozoários Malpighamoeba mellificae e Nosema apis (atualmente classificado como fungo); os nematoides Agamomermis sp. e Gordius sp., a bactéria Melissococcus pluton, atualmente Melissococcus plutonius; o fungo Aschosphaera apis; os parasitas Acarapis woodi e Varroa jacobsoni (atualmente Varroa destructor); os vírus Filamentous virus, Acute paralysis virus (ABPV), Black queen cell virus (BQCV) e Cloudy wing vírus (CWV); as moscas Melaloncha ronnai, Sarcophaga surrubea e Braula coeca; as traças Achroia grisella e Galleria mellonela; o percevejo Apiomerus lanipes e a formiga Myrmeleon januarius.

Os principais agentes responsáveis por atingir as abelhas adultas no Brasil são a nosemose, causada pelo fungo Nosema apis, e a varroatose, causada pelo ácaro Varroa destructor, o qual ataca tanto as crias quanto as abelhas adultas. Doenças em crias geralmente causam maiores danos às colmeias do que às abelhas adultas e, por isso, costumam causar mais prejuízos. As principais doenças que afetam crias de abelhas africanizadas, no Brasil, são a Cria Pútrida Europeia, a Cria Giz e a Cria Ensacada Brasileira (PEREIRA et al. 2004).

O surgimento de várias doenças e fenômenos, como Colony Collapse Disorder (CCD), tem sido a causa de muitas perdas para a apicultura em algumas regiões do planeta. O CCD é um abandono repentino 
e massivo de colmeias (OLDROYD 2007). Esse fenômeno provocou o desaparecimento da população de abelhas nas colmeias nos Estados Unidos a partir do ano de 2006 e se expandiu pelo mundo. Aparentemente, apresenta como causas a intoxicação por inseticidas, a ocorrência de viroses, a infestação pelo fungo do gênero Nosema, problemas com a variabilidade genética e a seleção das abelhas, o surgimento do ácaro Varroa destructor - haplótipo K, a falta de alimentos energéticos e proteicos adequados na colônia e sistemas de manejo intensivo das colmeias (DE JONG 2009).

No Brasil, apicultores de Santa Catarina, Minas Gerais, São Paulo e Rio Grande do Sul já relataram casos suspeitos de CCD em suas propriedades. Segundo PIRES et al. (2016), somente dois casos com características semelhantes às descritas para CCD foram registrados, porém sem uma conclusão definitiva. A ausência desse fenômeno no Brasil possivelmente está ligada à procedência de nossas abelhas (africanizadas), as quais aparentam ser mais resistentes que as abelhas de origem europeia, encontradas em outras partes do mundo (ARIOLI et al. 2014).

A intensificação da produção a todo custo, a migração de apiários e o comércio de abelhas (rainhas e enxames), bem como o uso inadequado das técnicas de manejo, também favorecem a ação de inimigos naturais e o depauperamento das colônias. Esses fatores, aliados ao uso de equipamentos não recomendados, à carência de boas práticas sanitárias e de produção, ao fracasso no reconhecimento e manejo das doenças nas colmeias pelos apicultores, são preponderantes para a redução da resistência natural das colmeias. Como consequência, o uso desse conjunto de práticas inadequadas contribui diretamente para a rápida disseminação de vetores de doenças e pragas na apicultura.

\section{0 uso de agrotóxicos}

Os recentes declínios mundiais em populações de abelhas e a crescente demanda de polinização por insetos para diversas culturas levantam preocupações sobre o declínio das populações de polinizadores. Tais achados são de grande preocupação, dado o grande número e altos níveis de pesticidas encontrados no mel e nas colônias de abelhas (PETTIS et al. 2013).

Segundo SPADOTTO et al. (2004), o uso de agrotóxicos no Brasil passou de 16 mil toneladas em 1964 para mais de 128 mil toneladas em 1998. Além disso, nos últimos 40 anos, o uso desses insumos aumentou $700 \%$ enquanto a área agrícola teve um acréscimo de apenas $78 \%$. Com esse panorama, o Brasil é o país que mais utiliza agrotóxicos, em termos de quantidade total. Segundo a Agência Nacional de Vigilância Sanitária (Anvisa), anualmente são utilizadas mais de um milhão de toneladas, o que corresponde ao consumo de mais de um bilhão de litros (ANVISA 2012).

As abelhas são de particular interesse, pois entram em contato com vários poluentes durante a atividade de forrageamento, tornando-se um agente perfeito em estudos e bioensaios para o monitoramento da toxicidade de metais pesados e pesticidas, tanto em áreas urbanas como em áreas rurais (SMITH \& WILCOX 1990). O efeito drástico de agrotóxicos, em particular de inseticidas, não se limita à morte de organismos não alvo, mas está relacionado com o comportamento anormal e com a função a que eles induzem (Tabela 1).

Diversos estudos ao redor do mundo demonstram o perigo da utilização indiscriminada de agrotóxicos, os quais vêm lentamente suprimindo as populações de polinizadores (Tabela 1). Em pesquisas recentes, 121 pesticidas e diferentes metabolitos foram identificados em colmeias com uma média de sete pesticidas por amostra de pólen, incluindo acaricidas, inseticidas, fungicidas, herbicidas e reguladores de crescimento de insetos (MULLIN et al. 2010). Mesmo em concentrações baixas, muitas vezes os agrotóxicos afetam a estrutura e a função das comunidades naturais, provocando impactos em múltiplos níveis, que vão desde o molecular até o de comunidades inteiras, comprovando que as práticas agrícolas intensivas são altamente impactantes ao ambiente e estão diretamente relacionadas à redução da biodiversidade (GRISOLIA 2005).

Devido ao alto grau de susceptibilidade apresentado pelas populações polinizadoras, os períodos de floração merecem atenção especial no que diz respeito ao uso de substâncias químicas. Dessa forma, torna-se imprescindível a proteção de forma integral das abelhas nessas situações. A densidade e a atratividade das flores de plantas em pleno florescimento contaminadas pela aplicação de determinados agrotóxicos são as principais causas de morte desses insetos, porém baixos níveis de doses ou baixas frequências de aplicação podem afetar o comportamento das abelhas forrageiras e reduzir o vigor da colônia (BORTOLOTTI et al. 2003). Ratificando isso, MALASPINA et al. (2008) relatam que não são apenas os efeitos de toxicidade aguda que podem provocar a morte das abelhas; os inseticidas podem também provocar alterações comportamentais nos indivíduos, que, ao longo do tempo, acarretarão sérios prejuízos na manutenção e no desenvolvimento da colônia.

Segundo PIRES et al. (2016), em algumas circunstâncias, o efeito de inseticidas nas abelhas não 
pode ser imediatamente notado, sendo necessária a utilização de diferentes métodos de avaliação empregando doses subletais ou trabalhos de campo em longo prazo. Dessa forma, torna-se possível observar a influência desses compostos na sobrevivência, na fisiologia e no comportamento desses insetos sociais.

Tabela 1. Resultados encontrados em pesquisas utilizando diferentes métodos e testes toxicológicos em abelhas.

Table 1. Results found in studies using different methods and toxicological tests in bees.

\begin{tabular}{|c|c|c|c|}
\hline Espécie & Tipo de exposição & Resultado encontrado & Autor \\
\hline A. mellifera & $\begin{array}{l}\text { Exposição oral com teste de } \\
\text { reflexo }(\mathrm{PER})^{1}\end{array}$ & $\begin{array}{l}\text { Administração aguda e crônica de neonicotinoides } \\
\text { prejudicam o aprendizado olfatório e a memória } \\
\text { das abelhas. }\end{array}$ & $\begin{array}{l}\text { DECOURTYE et al. } \\
(2004)\end{array}$ \\
\hline A. mellifera & $\begin{array}{l}\text { Pulverização em campo e } \\
\text { avaliação dos insetos }\end{array}$ & $\begin{array}{l}\text { Redução do desenvolvimento das crias e perda } \\
\text { significativa do vigor das colônias. }\end{array}$ & PMRA (2006) \\
\hline B. terrestris & $\begin{array}{l}\text { Exposição oral com teste de } \\
\text { reflexo de extensão da } \\
\text { probóscide (PER) }\end{array}$ & $\begin{array}{l}\text { Exposição crônica a neonicotinoides e piretroides } \\
\text { prejudica o forrageamento e aumenta a } \\
\text { mortalidade de operárias, reduzindo o } \\
\text { desenvolvimento da ninhada e o sucesso da } \\
\text { colônia. }\end{array}$ & GILL et al. (2012) \\
\hline
\end{tabular}

A. mellifera Coleta e avaliação de pólen Exposição a pesticidas resultam em aumento do PETTIS et al. (2013) contaminado e oferecimento patógeno $N$. ceranae no intestino de abelhas às abelhas melíferas, fato que contribui para o declínio das colônias.

\begin{tabular}{llll}
\hline A. mellifera & Exposição oral em laboratório & Doses subletais de pesticidas colinérgicos & WILLIAMSON \& \\
mellifera & combinados prejudicam o forrageamento e & WRIGHT (2013) \\
& resultam na redução da população devido à falha & \\
& da função neural de abelhas.
\end{tabular}

\begin{tabular}{|c|c|c|}
\hline $\begin{array}{l}\text { A. mellifera } \\
\text { ligustica }\end{array}$ & $\begin{array}{l}\text { Avaliação de toxicidade oral } \\
\text { crônica }\end{array}$ & $\begin{array}{l}\text { Pesticidas e suas misturas, aditivos de } \\
\text { formulações e interações sinérgicas podem ter } \\
\text { maiores impactos em longo prazo sobre a saúde } \\
\text { das colmeias do que era considerado até o } \\
\text { momento. }\end{array}$ \\
\hline
\end{tabular}

\begin{tabular}{llll}
\hline $\begin{array}{l}\text { A. mellifera } \\
\text { intermissa }\end{array}$ & $\begin{array}{l}\text { Pulverização em campo e } \\
\text { avaliação dos insetos }\end{array}$ & $\begin{array}{l}\text { Comprovada inibição da atividade da enzima } \\
\text { acetilcolinesterase (AChE) nas abelhas. }\end{array}$ & NABTI et al. (2014) \\
\hline A. mellifera & $\begin{array}{l}\text { Monitoramento de inseticidas } \\
\text { em abelhas mortas em }\end{array}$ & $\begin{array}{l}\text { Concentrações de clorpirifós e dimetoato estão } \\
\text { altamente relacionadas com os picos de }\end{array}$ & $\begin{array}{l}\text { CALATAYUD- } \\
\text { VERNICH et al. }\end{array}$ \\
& apiários no período de floraçãomortalidade de abelhas em frente às colmeias. & $(2016)$
\end{tabular}

\begin{tabular}{|c|c|c|}
\hline A. mellifera & $\begin{array}{l}\text { Monitoramento de } 150 \\
\text { ingredientes ativos e três } \\
\text { vírus em abelhas mortas }\end{array}$ & $\begin{array}{l}\text { 100\% das amostras de abelhas mortas foram } \\
\text { detectadas com viroses e } 75,8 \% \text { com agrotóxicos. (2017) } \\
\text { Em hipótese, o estresse combinado entre } \\
\text { enfermidades e agrotóxicos é um fator } \\
\text { preponderante na redução dos mecanismos de } \\
\text { defesa natural e na mortalidade das abelhas. }\end{array}$ \\
\hline
\end{tabular}

${ }^{1}$ PER: Teste de reflexo da extensão da probóscide.

DECOURTYE et al. (2005) verificaram que os inseticidas deltametrina (piretroide), fipronil (neonicotinoide) e dimetoato (organofosforado) afetam de forma negativa a capacidade de aprendizagem das abelhas Apis mellifera L. com redução de reflexos na distensão da probóscide. Segundo os mesmos autores, em estudos no ano de 2004, pôde-se concluir que a toxicidade do grupo químico dos neonicotinoides também causa prejuízos à memória olfativa de abelhas (Tabela 1).

Em menos de 20 anos, os neonicotinoides se tornaram a classe de inseticida mais utilizada, com uma quota de mais de $25 \%$ do mercado global (VAN DER SLUIJS et al. 2013). Novos estudos, nos quais as abelhas foram expostas a inseticidas em laboratório ou foram utilizadas dietas artificias contaminadas, têm demonstrado a ocorrência de efeitos subletais após exposição a esses produtos. Entre os principais efeitos Rev. Ciênc. Agrovet., Lages, SC, Brasil (ISSN 2238-1171) 
podemos citar a diminuição do sucesso de forrageamento de abelhas melíferas (HENRY et al. 2012), a redução do crescimento da colônia e de produção de abelhas rainhas (GILL et al. 2012). Além disso, SCOTT-DUPREE et al. (2009) relataram que aplicações foliares de inseticidas neonicotinoides, deltametrina ou spinosad também alteram o processo normal de forrageamento. BAPTISTA et al. (2009) observaram que o inseticida acefato (organofosforado) apresentou toxicidade para operárias adultas de $A$. mellifera quando houve pulverização direta sobre as abelhas, fornecimento de dieta contaminada e contato das abelhas com superfícies tratadas. Segundo PIRES et al. (2016), perdura a escassez literária de dados de avaliações de tais moléculas em campo ou semicampo nas condições ambientais brasileiras, e também a escassez de avaliações dos efeitos subletais em todas as fases de desenvolvimento das abelhas.

Além dos inseticidas, os herbicidas têm contribuído de forma indireta para a redução das populações de abelhas, principalmente das abelhas selvagens. Com o advento dos cultivos transgênicos, resistentes à aplicação de herbicidas, tem-se observado uma redução considerável de plantas espontâneas que florescem a partir das margens das áreas de cultivos, as quais possuem importância primária na coleta de pólen e néctar pelos polinizadores. Segundo JOHNSON et al. (2010), há um crescente aumento nas evidências de que essa escassez pode ocasionar má nutrição e, consequentemente, redução das populações de abelhas que circundam essas áreas agrícolas.

A espécie $A$. mellifera tem muitas vezes servido como representante de todos os polinizadores no processo de registro e estudo de pesticidas, embora a toxicidade desses compostos para outras espécies de abelhas possa ser diferente (BIDDINGER et al. 2013). DESNEUX et al. (2007) afirmam que as abelhas (Apoidea) fazem parte de um grupo muito diversificado, distribuídas em diferentes grupos taxonômicos, e apresentam vulnerabilidade variada no que diz respeito aos agrotóxicos.

Em casos extremos, as aplicações massivas de pesticidas podem dizimar as populações de diferentes espécies polinizadoras. Em algumas províncias do sudeste da China, os agentes polinizadores naturais desapareceram graças ao uso desenfreado desses xenobióticos. Nessas regiões, observam-se agricultores polinizando de forma manual, flor por flor, as árvores frutíferas (FAEP 2014).

Embora ainda nenhum pesticida ou grupo específico tenha sido indicado como causador do desaparecimento das populações de abelhas, o uso e os efeitos sinérgicos dos agrotóxicos, bem como os diferentes tipos de exposição, podem contribuir para o declínio da saúde das abelhas (JOHNSON et al. 2010).

\section{Desenvolvimento de uma apicultura sustentável}

O aproveitamento da potencialidade natural do meio ambiente e de sua capacidade produtiva torna a apicultura um fator de diversificação da propriedade rural. Essa atividade é considerada uma das grandes opções para a agricultura familiar nas mais variadas regiões do Brasil, favorecendo a geração de empregos e o aumento de renda, com benefícios sociais, econômicos e ecológicos.

A diversificação vegetal e o clima favorável em nosso país facilitam a exploração apícola, oferecendo condições de uma elevada produção. Por um lado, essa atividade mostra-se lucrativa, tanto para o apicultor quanto para as empresas que trabalham com as matérias-primas oriundas da apicultura. Por outro lado, a maioria dos apicultores brasileiros ainda trata a apicultura como uma atividade secundária, somente para complementar a renda familiar. Apesar da não exigência de cuidados diários nos apiários, tornam-se necessárias a capacitação e a profissionalização para que o maior potencial das colmeias possa ser atingido de forma a não comprometer a sanidade dos enxames.

A possibilidade de exploração dos produtos apícolas, tais como mel, pólen, própolis e cera, constituise em fonte de renda para agricultores de economia familiar tanto em regiões áridas, como o Nordeste brasileiro, quanto em regiões de invernos rigorosos, como as regiões serranas do Sul do Brasil. $O$ desenvolvimento dessa atividade também potencializa o manejo de abelhas direcionado para a polinização em áreas agrícolas; esse processo é fundamental na produção de frutos e sementes de várias espécies vegetais de interesse econômico e ambiental.

Sendo uma atividade nobre e das mais antigas, a apicultura é também considerada uma opção estratégica capaz de proporcionar positivamente impactos sociais, econômicos e ambientais, pois complementa a renda dos agricultores, garante a ocupação da mão de obra familiar e contribui de maneira efetiva para a conservação da flora nativa local sem a necessidade de desmatamentos ou êxodo rural (PASIN et al. 2012). Essa atividade pode ser integrada aos plantios florestais, de fruteiras, bem como de culturas anuais de ciclo curto. Nessa perspectiva, a apicultura pode contribuir para o aumento da produção agrícola, a regeneração da vegetação natural e a sustentabilidade dos agroecossistemas, gerando dividendos aos agricultores familiares. Além disso, a apicultura apresenta como vantagens não somente a geração de emprego e renda, mas também as facilidades quanto ao manejo, que não exige atividades 
diárias, o que permite ao apicultor integrar a prática apícola com outras fontes de renda na propriedade rural.

\section{Polinizadores: panorama atual e perspectivas}

Entre os serviços ecossistêmicos, a polinização pode ser considerada a base da manutenção de diversas culturas de importância agrícola, bem como a responsável pela perpetuação de diversas espécies vegetais dos mais variados ecossistemas da terra.

A agricultura de grande escala, em âmbito mundial, utiliza elevadas quantidades de insumos para atender o patamar de produção dos últimos anos. Por um lado, a maioria das pesquisas é direcionada para a necessidade de aumentar essa produtividade e saciar a crescente demanda do mercado. Por outro lado, é dada discreta relevância aos trabalhos desenvolvidos com o intuito de entender como os agrotóxicos e outros compostos usados de forma massiva vêm contribuindo para a redução da população de polinizadores.

Nas últimas décadas, os esforços científicos estavam voltados para os estudos de toxicidade sobre os insetos adultos através de aplicações tópicas e de ingestão. Porém, muitos desses trabalhos não detalham essa relação em longo prazo. Sugerem-se novos estudos que avaliem o sinergismo oriundo da presença de pragas e enfermidades nas colônias, a avaliação dos efeitos letais e subletais em insetos imaturos até a sua fase adulta, bem como o acompanhamento das gerações subsequentes nas colônias ao longo de várias safras.

A degradação do habitat e de locais de nidificação, a falta de informações a respeito da criação e do manejo sustentável de polinizadores nativos e os efeitos de agrotóxicos sobre as colônias estão entre as principais dificuldades encontradas para a conservação e uso racional dos polinizadores em diversos agroecossistemas. A paisagem pobre no entorno das colmeias também compromete o desenvolvimento das populações de abelhas, as quais ficam propensas à desnutrição, o que leva ao enfraquecimento dos enxames, facilitando, dessa forma, a entrada de agentes patogênicos e inimigos naturais nas colônias. Essas dificuldades são potencializadas em períodos de escassez e na ausência de manejo adequado e cuidados nutricionais por parte dos apicultores.

As pesquisas multidisciplinares que buscam entender as causas da grande mortalidade de abelhas começaram a ganhar força ao redor do mundo nos últimos anos (GOULSON et al. 2015). Isso se deve, principalmente, aos declínios de colônias ocorridos em diversos países, principalmente entre 2006 e 2010. Em alguns casos, apiários inteiros foram perdidos sem uma explicação conclusiva.

Em relação à pergunta central deste trabalho, destacamos que não existe uma simples explicação para esclarecer os recentes fenômenos de desaparecimento de polinizadores nativos e domesticados. Apesar do crescente consenso sobre o envolvimento de múltiplos fatores causais (POTTS et al. 2010, GOULSON et al. 2015), as interações subjacentes que afetam a saúde das abelhas e a insuficiência da colônia não estão totalmente resolvidas. Esses fatores podem ocorrer simultaneamente e apresentar alguma influência mútua. Parasitas e patógenos estão entre os candidatos, mas a degradação e a fragmentação vegetal, bem como a exposição letal e subletal aos pesticidas são fatores preponderantes para suprimir as populações de abelhas nativas e domesticadas.

É improvável a possibilidade abrupta de frear o uso de agrotóxicos na agricultura de grande escala em curto prazo. Dessa forma, torna-se necessário o desenvolvimento de um plano de manejo e a conscientização necessária para possibilitar a redução dessas cargas, principalmente em horários propícios ao forrageamento, garantindo menor exposição direta às populações de polinizadores. Recomenda-se também a utilização de moléculas menos agressivas aos polinizadores, bem como a constante investigação da toxicidade, do sinergismo e dos efeitos subletais dos agrotóxicos sobre esse importante grupo de insetos.

O desafio para a conservação da biodiversidade de polinizadores e seus serviços torna-se a cada dia mais importante à medida que observamos a perda ininterrupta de habitat, o avanço da agricultura extensiva, o manejo inadequado de nossas abelhas domésticas, bem como o crescente número de doenças e pragas que acometem os polinizadores.

Os resultados científicos, por si só, não resolvem os problemas relacionados aos polinizadores. Contudo, o conhecimento científico, integrado a ações sociais e governamentais, e métodos que busquem a proteção de polinizadores bem como o seu correto manejo, podem tornar mais harmoniosa a convivência entre polinizadores, plantas e seres humanos, resultando em benefícios mútuos.

\section{CONCLUSÃO}

A fragmentação ambiental, o uso de agrotóxicos, o manejo inadequado de colmeias e as crescentes 
infestações de pragas nas colônias são considerados os principais fatores relacionados ao desaparecimento das abelhas. Para minimizar a perda de polinizadores nativos e domésticos, recomenda-se a conservação e manutenção da paisagem natural circundante às áreas agrícolas e a profissionalização de apicultores no manejo nutricional e na conservação das colônias. Além disso, destacamos a necessidade do desenvolvimento de estudos criteriosos combinando pesquisas de laboratório e de campo para avaliar, de forma mais realista, os efeitos sinérgicos causados pela presença de pragas, enfermidades nas colônias e uso de agrotóxicos nos mais diversos agroecossistemas.

\section{AGRADECIMENTOS}

Agradecemos ao Conselho Nacional de Desenvolvimento Científico e Tecnológico (CNPq) pelos recursos através do Edital CNPq № 482262/2013-3 e pela bolsa de estudos (201568/2017-9).

\section{REFERÊNCIAS}

ANVISA. 2012. Agência Nacional de Vigilância Sanitária. Seminário volta a discutir mercado de agrotóxicos em 2012. Disponível em: http://www.scielo.br/scielo.php?script=sci_nlinks\&ref=000094\&pid=S1980-993X201400010000900003 \&lng=pt. Acesso em: $15 \mathrm{fev} .2017$.

ARIOLI CJ et al. 2014. Em busca de respostas ao sumiço das abelhas. In: Correio Rio grandense. Disponível em: https://www.infoteca.cnptia.embrapa.br/infoteca/bitstream/doc/996761/1/Botton.pdf. Acesso em: 15 mar. 2017.

BAPTISTA APM et al. 2009. Toxicidade de produtos fitossanitários utilizados em citros para Apis mellifera. Ciência Rural 39: 955-961.

BIDDINGER DJ et al. 2013. Comparative toxicities and synergism of apple orchard pesticides to Apis mellifera (L.) and Osmia cornifrons (Radoszkowski). PloS one 8: 6p.

BIESMEIJER JC et al. 2006. Parallel declines in pollinators and insect-pollinated plants in Britain and the Netherlands. Science 313: 351-354.

BORTOLOTTI L et al. 2003. Effects of sub-lethal imidacloprid doses on the homing rate and foraging activity of honey bees. Bulletin of Insectology 56: 63-68.

BRODSCHNEIDER R \& CRAILSHEIM K. 2010. Nutrition and health in honey bees. Apidologie 41: 278-294.

BROWN JC \& OLIVEIRA ML. 2014. The impact of agricultural colonization and deforestation on stingless bee (Apidae: Meliponini) composition and richness in Rondônia, Brazil. Apidologie 45: 172-188.

CALATAYUD-VERNICH P et al. 2016. Influence of pesticide use in fruit orchards during blooming on honeybee mortality in 4 experimental apiaries. Science of the Total Environment 541: 33-41.

COUTO RHN \& COUTO LA. 2002. Apicultura: manejo e produtos. 2.ed. Jaboticabal: FUNEP. 191p.

DECOURTYE A et al. 2004. Imidacloprid impairs memory and brain metabolism in the honeybee (Apis mellifera L.). Pesticide Biochemistry and Physiology 78: 83-92.

DECOURTYE A et al. 2005. Comparative sublethal toxicity of nine pesticides on olfactory learning performances of the honeybee Apis mellifera. Archives of environmental contamination and toxicology 48: 242-250.

DESNEUX N et al. 2007. The sublethal effects of pesticides on beneficial arthropods. Annual Review of Entomology. 52: 81-106.

DE JONG D. 2009. Desaparecimento de abelhas: pesticidas agrícolas afetam insetos, safras e saúde humana. Scientific American Brasil 84: 48-49.

FAEP. 2014. Federação da Agricultura do Estado do Paraná. O sumiço das abelhas. Curitiba: FAEP e SENAR. 30p. (Boletim técnico 1255).

GARIBALDI LA et al. 2013. Wild pollinators enhance fruit set of crops regardless of honey bee abundance. Science 339: 1608-1611.

GILL RJ et al. 2012. Combined pesticide exposure severely affects individual- and colony-level traits in bees. Nature 491: 105-108.

GRISOLIA CK. 2005. Agrotóxicos: mutações, câncer e reprodução. Brasília: UNB. 394p.

GOULSON D et al. 2015. Bee declines driven by combined stress from parasites, pesticides, and lack of flowers. Science 347: e1255957.

HENRY M et al. 2012. A common pesticide decreases foraging success and survival in honeybees. Science 336: 348350.

JOHNSON RM et al. 2010. Pesticides and honey bee toxicity-USA. Apidologie 41: 312-331.

KLEIN AM et al. 2007. Importance of pollinators in changing landscapes for world crops. Proceedings of the Royal Society of London B: Biological Sciences 274: 303-313.

KREMEN C et al. 2004. The area requirements on an ecosystem service: crop pollination by native bee communities in California. Ecology letters 7: 1109-1119.

MARCO JR P \& COELHO FM. 2004. Services performed by the ecosystem: forest remnants influence agricultural cultures pollination and production. Biodiversity and Conservation 13: 1245-1255.

MARTINELLO M et al. 2017. Spring mortality in honeybees in northeastern Italy: detection of pesticides and viruses in dead honeybees and other matrices. Journal of Apicultural Research 56: 239-254.

MESSAGE D et al. 2012. Situação da sanidade das abelhas no Brasil. In: FONSECA VLI et al. (Orgs.). Polinizadores no 
Brasil: contribuição e perspectivas para a biodiversidade, uso sustentável, conservação e serviços ambientais. São Paulo: EDUSP. p.237-256.

NEFF JL \& SIMPSON BB. 1993. Bees, pollination systems and plant diversity. Em: LASALLE J \& GAULD ID. (Ed.). Hymenoptera and biodiversity. Wallingford: CAB International. p.143-167.

LOSEY JE \& VAUGHAN M. 2006. The economic value of ecological services provided by insects. BioScience 56: $311-$ 323.

MALASPINA O et al. 2008. Efeitos provocados por agrotóxicos em abelhas no Brasil. Em: VIII Encontro Sobre Abelhas. Resumos... Ribeirão Preto: FUNPEC. p.41-48.

MULLIN CA et al. 2010. High levels of miticides and agrochemicals in North American apiaries: implications for honeybee health. PLoS one 5: 19p.

NABTI D et al. 2014. The toxic effect of the pesticides on Apis mellifera intermissa (Hymenoptera, Apidae): Glutathione S-Transferase Activity. European Journal of Experimental Biology 4: 121-125.

OLDROYD BP. 2007. What's killing American honey bees? PLoS biology 5: 1195-1199.

ORTH Al et al. 2012. Manejo da polinização e o problema da diminuição da população de abelhas domésticas. Agropecuária Catarinense 25: 47-52.

PASIN LEV et al. 2012. Análise da Produção de Mel Natural no Brasil no Período de 1999 a 2010. Revista Agroalimentaria 18: 29-42.

PAREJA L et al. 2011. Detection of Pesticides in Active and Depopulated Beehives in Uruguay. International Journal of Environmental Research and Public Health 8: 3844-3858.

PEREIRA FM et al. 2004. Doenças e Inimigos Naturais das Abelhas. Brasília: Embrapa. Disponível em: https://www.infoteca.cnptia.embrapa.br/bitstream/doc/68248/1/Doc103.pdf. Acesso em: 13 dez. 2016.

PETTIS JS et al. 2013. Crop pollination exposes honeybees to pesticides which alters their susceptibility to the gut pathogen Nosema ceranae. PloS one 8: 9p.

PIRES CSS et al. 2016. Enfraquecimento e perda de colônias de abelhas no Brasil: há casos de CCD?. Pesquisa Agropecuária Brasileira 51: 422-442.

PMRA. 2006. Proposed Registration Decision. Novaluron, Ottawa: Health Canada's Pest Management Regulatory Agency. Report No. PRD2006-05. 108p.

POTTS SG et al. 2010. Global pollinator declines: trends, impacts and drivers. Trends in Ecology and Evolution 25: 345-353.

POTTS SG et al. 2016. Safeguarding pollinators and their values to human well-being. Nature 540: 220-229.

RICKETTS TH et al. 2008. Landscape effects on crop pollination services: are there general patterns? Ecology Letters 11: 499-515.

ROUBIK DW. 1992. Ecology and natural history of tropical bees. 1.ed. New York: Cambridge University Press. 514p.

SALA OE et al. 2000. Global biodiversity scenarios for the year 2100. Science 287: 1770-1774.

SCOTT-DUPREE CD et al. 2009. Impact of currently used or potentially useful insecticides for canola agroecosystems on Bombus impatiens (Hymenoptera: Apidae), Megachile rotundata (Hymentoptera: Megachilidae), and Osmia lignaria (Hymenoptera: Megachilidae). Journal of Economic Entomology 102: 177-182.

SILVA JSV et al. 2010. Desmatamento na Bacia do Alto Paraguai no Brasil. Em: III Simpósio de Geotecnologias no Pantanal. Resumos... Cáceres: EMBRAPA/INPE. p.459-467.

SILVA NR. 2004. Aspectos do perfil e do conhecimento de apicultores sobre manejo e sanidade da abelha africanizada em regiões de apicultura de Santa Catarina. Dissertação (Mestrado em Agroecossistemas). Florianópolis: UFSC. $115 p$.

SMITH RK \& WILCOX MM. 1990. Chemical residues in bees, honey and beeswax. American Bee Journal 130: 188-192.

SPADOTTO CA et al. 2004. Monitoramento de risco ambiental de agrotóxicos: princípios e recomendações. Jaguariúna: EMBRAPA. 29p.

TILMAN D et al. 2001. Forecasting agriculturally driven global environmental change. Science 292: 281-284.

VAN DER SLUIJS JP et al. 2013. Neonicotinoids, bee disorders and the sustainability of pollinator services. Current Opinion in Environmental Sustainability 5: 293-305.

WILLIAMSON SM \& WRIGHT GA. 2013. Exposure to multiple cholinergic pesticides impairs olfactory learning and memory in honeybees. The Journal of Experimental Biology 216: 1799-1807.

ZHU W et al. 2014. Four common pesticides, their mixtures and a formulation solvent in the hive environment have high oral toxicity to honey bee larvae. PloS one 9: 11p. 